\title{
Demand for and access to family planning services among young married women during COVID-19 crisis
}

UNICEF

Population Council Institute

Follow this and additional works at: https://knowledgecommons.popcouncil.org/departments_sbsr-pgy

Part of the Demography, Population, and Ecology Commons, International Public Health Commons, and the Public Health Education and Promotion Commons How does access to this work benefit you? Let us know!

\section{Recommended Citation}

UNICEF and Population Council Institute. 2020. "Demand for and access to family planning services among young married women during COVID-19 crisis," COVID-19 Research Results Brief \#6. New Delhi: UNICEF and Population Council Institute. 
DEMAND FOR AND ACCESS TO FAMILY PLANNING SERVICES AMONG YOUNG MARRIED WOMEN DURING COVID-19 CRISIS
Current use of modern contraceptive methods was limited among young married women (14\%); it was even lower in neighbourhoods perceived to be at risk of COVID-19.

Among those who were not using any method, $11 \%$ expressed the need for modern methods and an additional $19 \%$ reported their inability to access FP services from health facilities due to lockdown.

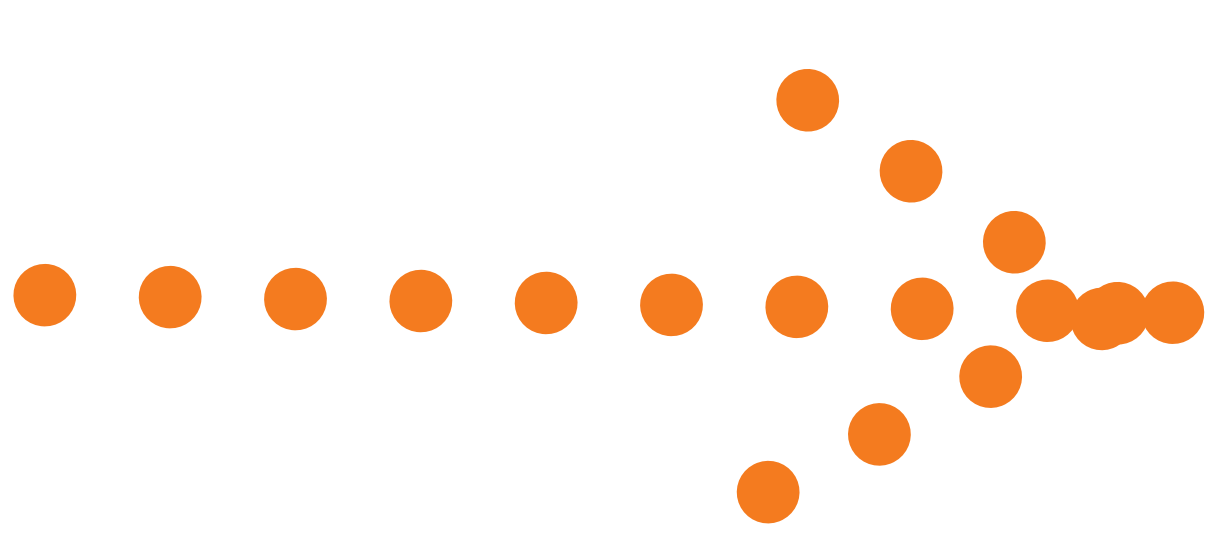

Access to family planning services was limited among marginalized communities than 'others' during the lockdown.

\section{BACKGROUND}

- With the COVID-19 lockdown and men returning home in large numbers and spending more time at home in high stress conditions, the need for contraceptive services could be higher.

- The months of March-May are considered as "lean season" when demand is typically low for family planning programmes in the states like Bihar in northern India. However, higher demand caused by the lockdown and lack of access to health facilities has created a gap between demand and uptake. This could have negative consequences like high number of unintended pregnancies, unsafe abortions, and maternal mortality.

\section{METHODS}

- Data was gathered between May 13-22, 2020 from the existing study cohort of households under project UDAYA (www.projectudaya.in).

- Consented telephone interviews were conducted with a total of 310 currently married women.

\section{STUDY PARTICIPANTS PROFILE}

Participants were between 18-26 years of age.

On an average, participants had 2 children in their household.

About 17\% belonged to SC/ST communities.

\section{MODERN CONTRACEPTIVE USE}

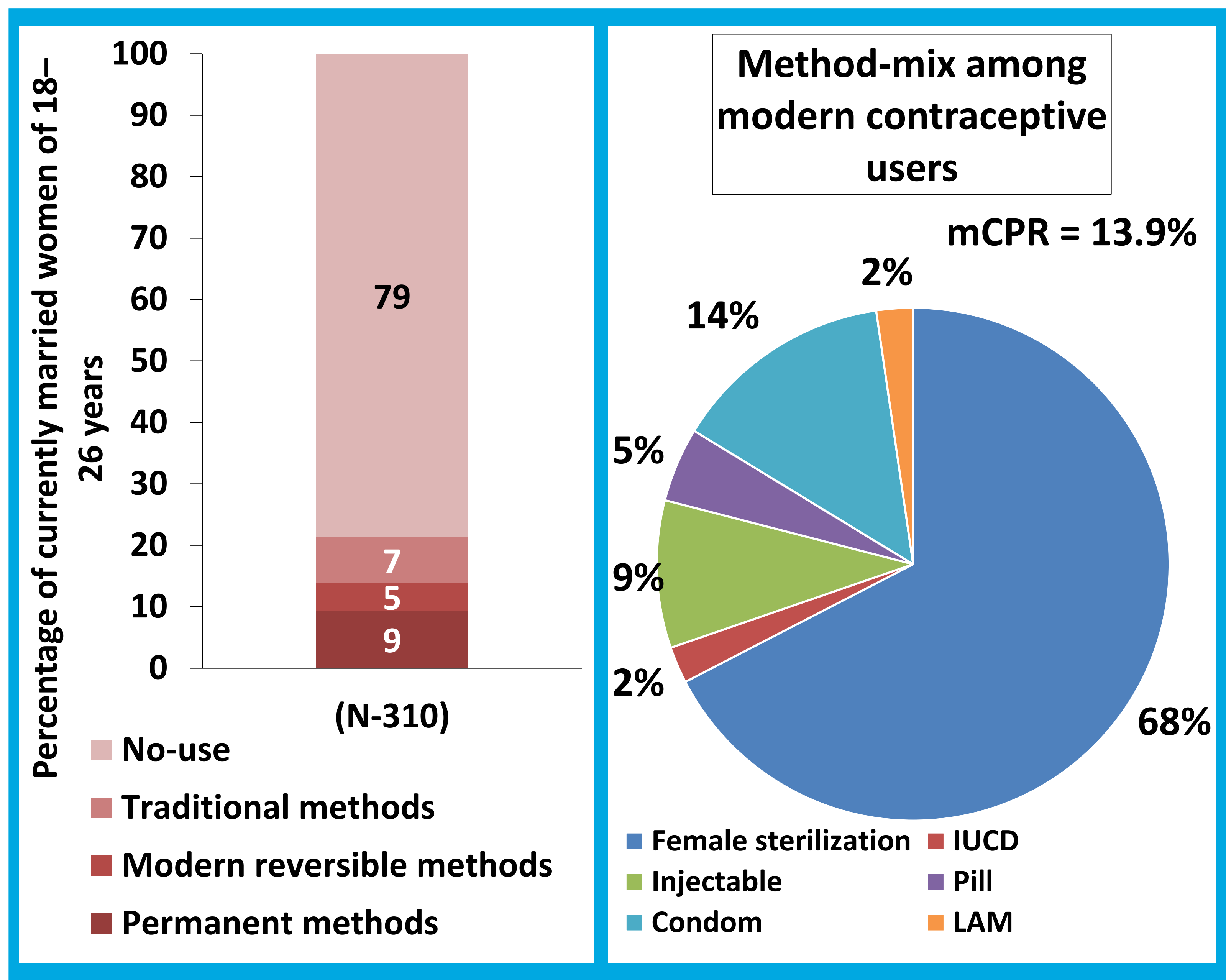

$21 \%$ of currently married women aged $18-26$ years were using any contraceptive method during COVID pandemic.

- The modern contraceptive use was only $14 \%$

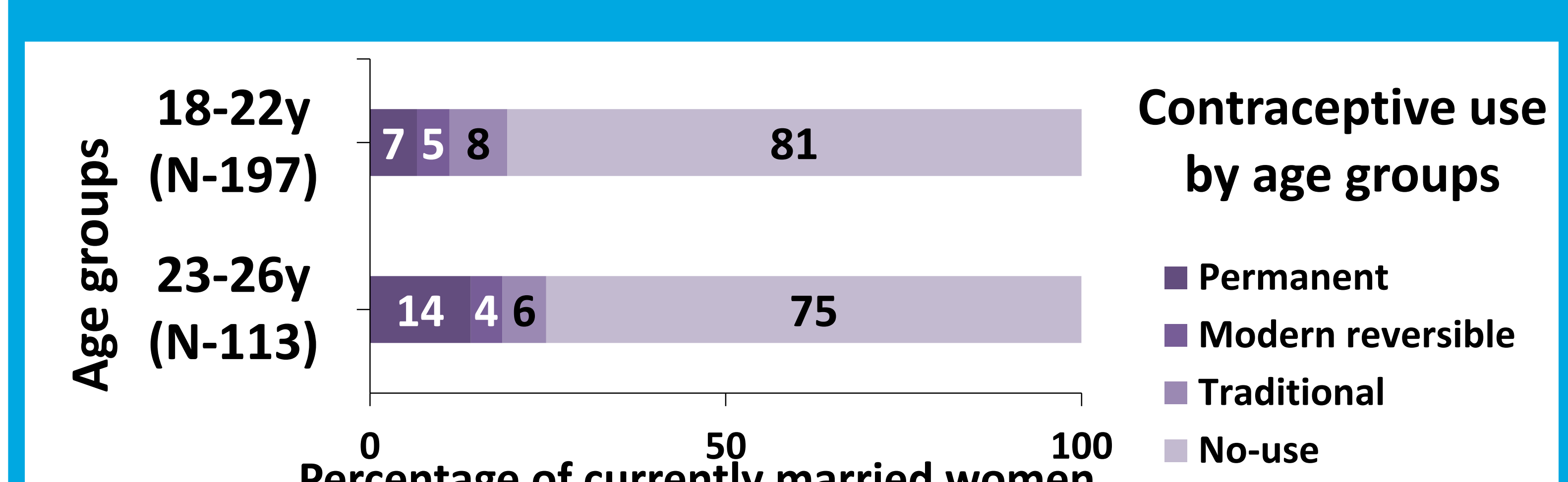

$\stackrel{0}{0} \begin{gathered}50 \\ \text { Percentage of currently married women }\end{gathered}$

\section{EFFECT OF COVID-19 ON CONTRACEPTIVE DEMAND AND ACCESS}

- Overall, $11 \%$ non-users and those using traditional methods reported the need for modern contraceptives during lockdown. An additional $19 \%$ of the respondents tried to access family planning services from nearby facilities but were unable to do so due to lockdown.

- Demand for family planning services was higher among women who belonged to socially disadvantaged castes and tribes than 'others'.

- Although not significant statistically, poorer families have reported higher need as well as limited access to family planning methods to health facilities due to lockdown.

- The reported need was higher among women living in areas where the respondents perceived risk to COVID-19 in the neighborhood.

The use of modern reversible method was worst affected (0\% vs $5 \%$ ) in those areas where women perceived risk of COVID-19 in the neighborhood.

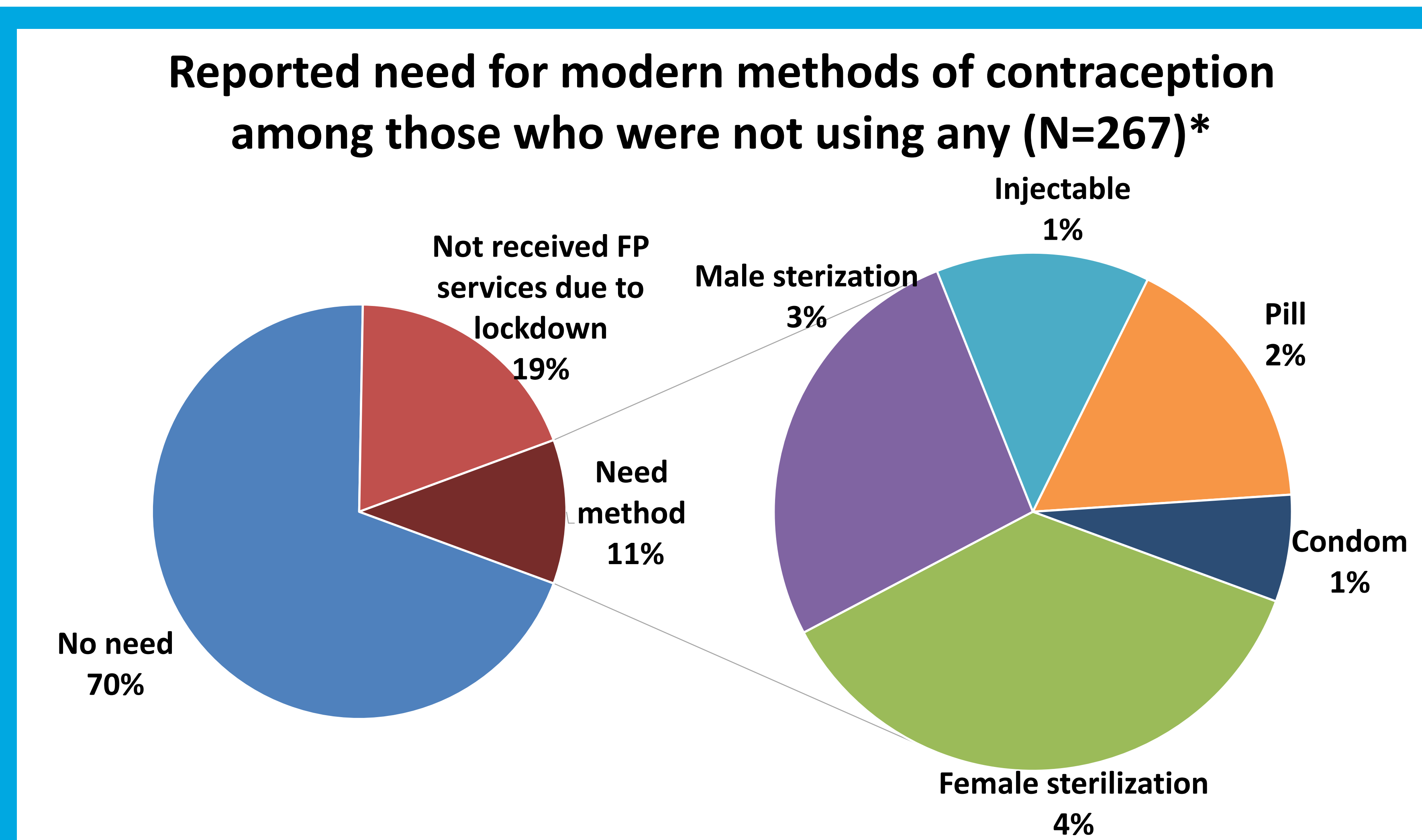

* Calculated among non-users and users of traditional methods

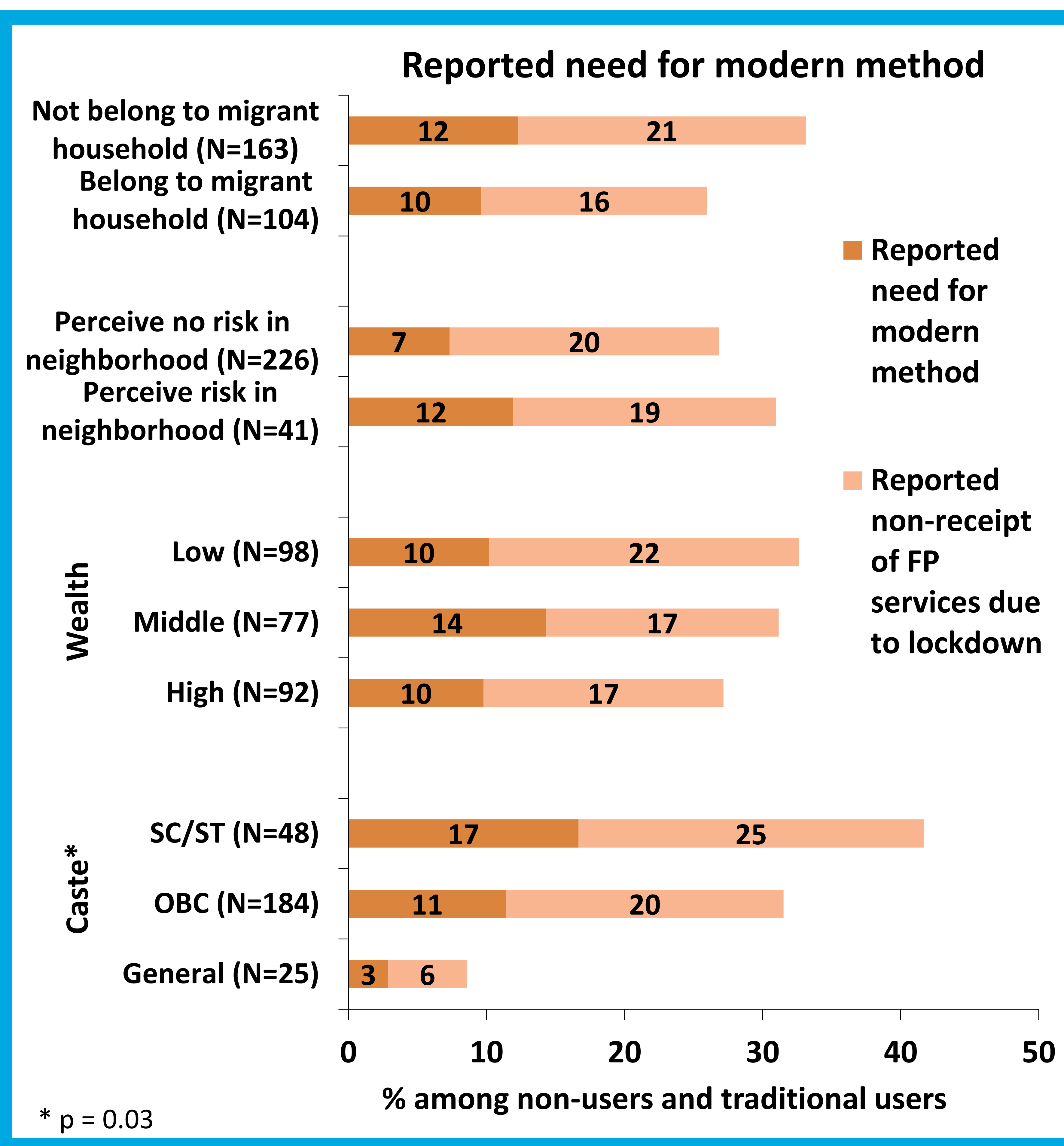

Perceived risk of COVID-19 in the area and contraceptive

Perceived risk of COVID-19 in the area and contraceptive use

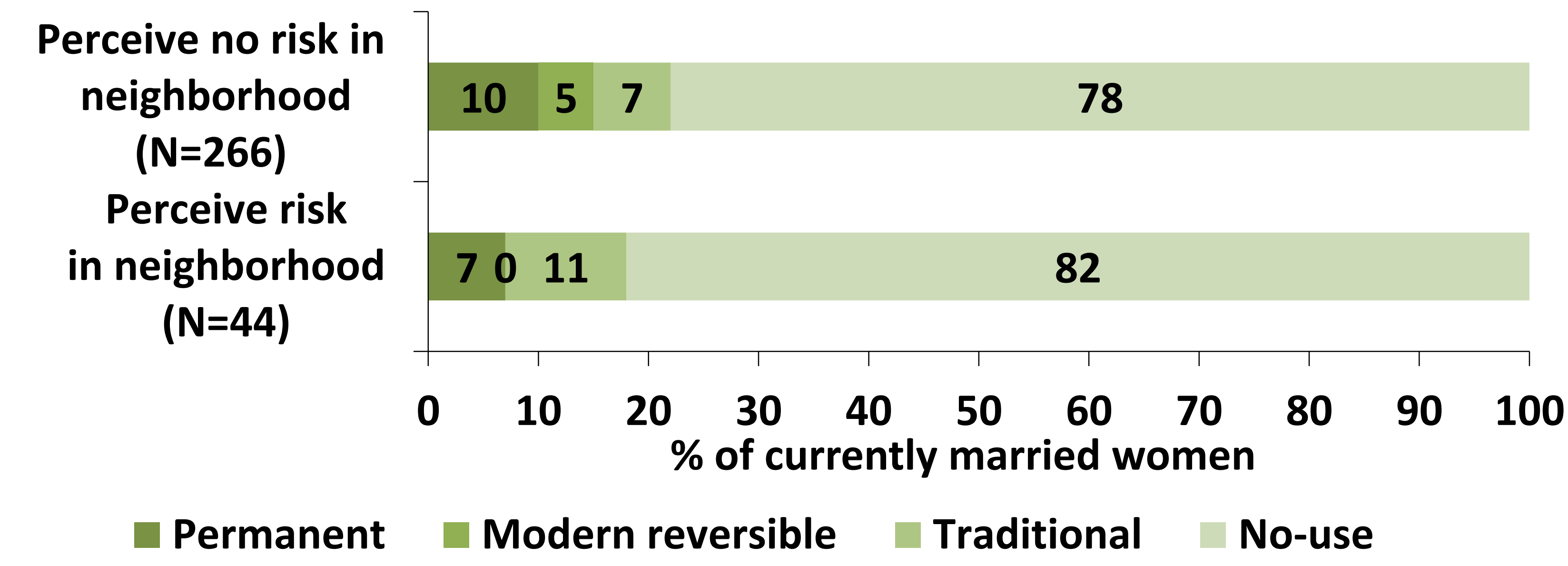

- Permanent $\square$ Modern reversible $\square$ Traditional $\square$ No-use

\section{LIMITATIONS}

- The contraceptive need assessed in the survey referred to a single question of whether or not the women wanted a method to avoid pregnancy (among those not using any method currently). Additionally, due to the lockdown and limited mobility, many women who were not using any method currently but not explicitly stated as needing contraceptives, reported that they could not get access to contraceptive methods. While the reasons for not stating the need is unknown, the in-depth analyses suggested that majority were using traditional methods at the time of survey.

\section{CONTACT INFORMATION}

This work was jointly undertaken by Population Council Institute and UNICEF/Bihar. 